\title{
Prevensi Terhadap Kekerasan Berbasis Jender
}

\author{
Qurotul Uyun \\ Universitas Islam Indonesia
}

\begin{abstract}
This article was written based on literatures on violence towards women, particularly domestic violence. The author offars range of efforts which should be made in the attempt to minimize gender violence. Many activities have been developed by non govemment onganizations (non profits) such as through their centers to assist women in crisis. Besides, the acts for anti violence towards women hal also been ratified. However, the solution at the policy level has not been able to reduce the number of domestic vilence. Many domestic violence cases remain unexplored as a result of the still existing taboo that domestic problems should not be exposed for public. Beside this value, there is a cultural basis that explains why preventing domestic violence remain difficult. Domestic violence, when explored further, has its cultural root, in the way men place himself as the "person in control" of his spouse (wife/woman). The attempt to prevent the widespread of domestic violence need to consider this cultural root, in order to achieve its goals more effectively. Programs for domestic violence prevention needs to aim at changing gender inequity idaology more seriously. Women rights issue need to be listed in the gender education programs within communities, commonly socialized through campaigns and trainings in gender issues.
\end{abstract}

Key Words: Gender violence, domestic violence, cultural basis, prevention

\section{PENGANTAR}

$S_{p}^{a+n}$ alah satu bentuk kerasan terhadap perempuan adalah kekerasan yang dilakukan suami kepada istrinya. Banyak kasus-kasus kekerasan terhadap istri yang diungkapkan melalui media cetak dan elektronik. Berita mengenai kekerasan terhadap istri di antaranya dapat dibaca dalam judul-judul berita di koran, sepertj "Aniaya Istri Dilaporkan Polisi" (Kedaulatan Rakyat ${ }_{s}$ 11-22004) "Tersangka Pembakar [stri, Stress" (Kedaulatan Rakyat. 12-2-2004); Hamil 5 Bulan, Emi Ditikam Suami" (Kedaulatan Rakyat, 16-2-2004). Selain itu berita Menteri
Negara Pemberdayaan Perempuan (MENEG PP) menyebutkan bahwa $50 \%$ perempuan menikah lulusan SD di pedesaan cenderung menerima kekerasan berupa pe-mukulan dari suami mereka, dengan salah satu alasan dari menghanguskan makanan, bertengkar dengan suami, pergi tanpa ijin suami, menelantarkan anak-anak, menolak hubungan seks dengan suami, (www. menegpp.go.id, 06-02-2004). Sumber tersebut juga menyebutkan bahwa satu dari tiga perempuan pernah dipukul, dipaksa melakukan hubungan seksual, mengalami penyiksaan suami, satu dari 
empat perempuan mengalami penyiksaan saat kehamilan, serta jutaan perempuan memerlukan pengobatan medis akibat kekerasan berbasis jender ini. Hasil studi eksploratif of daerah Indramayu dilakukan oleh Sulastri (2001) menemukan faktor-faktoryang menyebabkan kekerasan terhadap istri oi antaranya ketidakpuasan seksual terhadap istri. pertengkaran soal uang, istri menolak hubungan seksual, istri menolak keinginan suami, suami ingin kawin lagi, suami berselingkuh, suami sering berjudi, suami mabuk, suami sering ke tempat pelacuran. Data-data tersebut menggambarkan bahwa kekerasan yang dilakukan suami kepada istrinya lebih banyak disebabkan oleh konstruksi budaya yang membentuk dominansi pria kepada wanita.

Kenyataan tersebut merupakan kondisi yang sangat memprihatinkan, sehingga dalam beberapa tahun ini banyak dilakukan upayaupaya untuk mengatasi kekerasan terhadap perempuan. Pengakuan terhadap hak-hak perempuan sudah banyak diberlakukan secara hukum, Seperti perundang-undangan mengenai kekerasan terhadap perempuan. Banyak LSM-LSM, pusat penanganan kekerasan terhadap perempuan (Women Crisis Center) telah membantu menyelesaikan kasus-kasus kekerasan terhadap perempuan. Selain itu pemerintah saat ini sedang meningkatkan komitmen untuk menghapus kekerasan yang dikenal dengan zero tolerance policy (tidak ada toleransi sama sekali untuk kekerasan). Upaya-upaya tersebut dilakukan melalui pendekatan terhadap korban kekerasan, sehingga belum mampu mengurangi tingkat kekerasan yang terjadi di masyarakat. Kekerasan belum sepenuhnya disadari oleh masyarakat baik oleh laki-laki maupun perempuan sendiri sebagai korban kekerasan. Hal ini disebabkan karena secara kultural lakilaki sering dimaklumi sebagai pihak yang harus mengendalikan perilaku perempuan (istri), sementara perempuan harus selalu menuruti kehendak suami. Berdasarkan kasuskasus di atas, dapat dikatakan bahwa faktor penyebab kekerasan sering berawal dari kelidakpuasan suami terhadap pelayanan istri. Karena secara kultural istri harus melayani suami, akibatnya perempuan sering menjadi korban kekerasan laki-laki, tanpa disadari oleh keduanya. Melihat kompleksitas per-masalahan tersebut, pertu diupayakan pencegahan tindak kekerasan terhadap istri, melalui berbagai bentuk pendidikan atau penyadaran yang berkaitan dengan kekerasan terhadap perempuan.

\section{Pengertian Kekerasan Terhadap Istri}

Beberapa istilah yang berkaitan dengan kekerasan terhadap istri di antaranya Kekerasan Dalam Rumah Tangga (KDRT), wife abuse, wife battering, wife beating, spouse abuse, domestic violence, violence against women. Secara umum kekerasan istri dapat berupa kekerasan fisik dan kekerasan psikologis.

Cookfair(1996) mengung-kapkan bahwa kekerasan terhadap istri terdiri dari kekerasan fisik, kekerasan psikologis, dan kekerasan seksual. Pertama, kekerasan fisik (physical abuse) merupakan kekerasan yang dilakukan berulang-ulang seperti mendorong, mendesak, menampar, menendang, menyerang dengan senjata, menahan, serta menolak untuk membantu. Kedua, kekerasan emosional atau psikologis (emotional or psychological abuse) yang mungkin didahului atau bersamaan dengan kekerasan fisik, seperti mengancam akan melukai fisik, mengisolasi, cemburu atau bertindak posesif, merampas, mengintimidasi, menghina, terus menerus mengkritik. Ketiga, kekerasan seksual (sexual abuse) yang mungkin berbentuk pemaksaan secara seksual.

Hasil penelitian Djannah dkk (2003) mengungkapkan ketiga bentuk kekerasan tersebut, serta menam-bahkan bentuk kekerasan ekonomi, berupa perilaku suami yang membatasi istri untuk bekerja untuk menghasikan uang dan atau membiarkan istri bekerja untuk dieksploitasi; atau menetantarkan anggota keluarga dalam arti tidak memenuhi kebutuhan ekonomi keluarga. Jadi 
kekerasan ekonomi dapat menimpa istri bekerja maupun tidak bekerja.

Berdasarkan penjelasan di atas, dapat dikatakan bahwa perempuan sangat rentan terhadap berbagai macam bentuk kekerasan. Kekerasan dapat melanda siapapun tanpa mengenal status sosial, sehingga pasangan yang berasal dari status menengah ke atas, bahkan istri bekerja pun memiliki resiko terkena kekerasan.

\section{Akibat Kekerasan Terhadap istri}

Akibat dari kekerasan dapat mempengaruhi kesehatan fisik dan mental perempuan. Population Reports melaporkan bahwa kekerasan terhadap perempuan dapat memunculkan problem kesehatan, di antaranya sakit parah, cacat fisik, ketergantungan pada obat-obatan, dan depresi (mwwinfofothealth. 18-2-2004).

Hal tersebut dikemukakan juga oleh (Nevid, dkk. 1997) bahwa kekerasan terhadap istri mempunyai resiko luka fisik bahkan dapat menyebabkan kematian, selain itu juga dapat berakibat posttraumatic stress disorders (PTSD), serta akibat psikologis yang lain, terutama depresi dan harga diri yang rendah. Lips (1988) menyatakan bahwa wanita korban kekerasan sering menjadi terasing dari orang lain serta tumbuh perasaan tidak mampu ( $p$ owerlessness) dan lidak berdaya (helplessness) karena gagal untuk menghentikan tindak kekerasan yang dilakukan suaminya. Nevid dkk. (1997) juga menambahkan bahwa ada sejumlah harapan yang ditumpukan kepada wanita, yaitu bahwa secara kulkural wanita diharapkan untuk mengobankan dirinya demi keutuhan rumah tangga, serta menjaga anakanak dari perasaan tidak aman. Permasalahan ini sering membuat wanita harus selalu menerima terhadap tindak kekerasan suaminya.

Paparan di atas menggam-barkan bahwa wanita mengalami dilema dalam menghadapi tindak kekerasan suaminya, yaitu antara keinginan untuk lepas dari hubungan yang penuh kekerasan dengan keharusan mem- pertahankan rumah tangga dan anak-anaknya. Dilema terse but menim-bulkan perasaan sakit hati yang berakibat lanjut perasaan bersalah, tidak berdaya dan depresi ataupun gangguan psikologis lainnya.

\section{Pendekatan Kultur Sosial Terhadap Kekerasan Pada Perempuan}

Pendekatan kultur sosial terhadap kekerasan pad a perempuan sering disebut gender-based violence atau gender-related violence (Fakih dalam Bainar, 1998) berasumsi bahwa kekerasan terhadap perempuan merupakan bentuk subordinasi terhadap perempuan dalam masyarakat. Budaya patriarkhi telah membentuk ketidakadilan jender, sehingga perempuan rentan mendapatkan kekerasan dari suami. Kebanyakan budaya menganggap bahwa pria harus dominan terhadap perempuan. Selanjutnya Nevid (1997) menambah-kan bahwa laki-laki dapat menggunakan kekerasan untuk menunjukkan ke-kuasaannya, jika merasa kebutuhan dan keinginannya tidak dipenuhi. Nylen \& Heimer (1999) juga menjelaskan kekerasan dalam rumah tangga sebagai proses normalisasi yang digambarkan bahwa proses tersebut bagi pria merupakan strategi untuk mengendali-kan wanita dan membuktikan maskulinitasnya. Sedangkan bagi wanita proses normalisasi merupakan cara untuk merasionalisasi, meng-adopsi, menerima, dan mem-pertahankan perilaku pria, sehingga perempuan kurang memiliki kendali dalam menghadapi masalah. Hal itu dijelaskan lebih lanjut oleh Richmon (1992) bahwa kekerasan terhadap istri melam-bangkan kekuasaan laki-laki dan penerimaan perempuan. Perempuan dianggap milik laki-laki dan laki-laki mempunyai kekuasaan atas diri mereka, akibatnya banyak laki-laki merasa mempunyai hak untuk berbuat kekerasan terhadap istri, sedangkan kebanyakan perempuan diharapkan untuk menerima kekerasan terse but. Asumsi tersebut didukung oleh penelitian Yoshioka dkk. (2001) yang menyimpulkan bahwa keluarga pada ma- 
syarakat Asia cenderung patriarkhis dan hirarkhis, sehingga memberi hak yang sangat besar kepada suami atas istri dan anakanaknya, akibatnya penggunaan kekerasan sering dipandang sebagai hak prerogalif suami.

Interpretasi terhadap ajaran agama memunculkan anggapan bahwa posisi pria lebih tinggi dari wanita, misalnya suami dianggap wajib mendidik istrinya, meskipun istrinya lebih pintar dan lebih berakhlak. Akibat pemahaman tersebut suami dianggap boleh memukul istrinya dengan dalih mendidik. Jolok ukur istri yang baik menurut anggapan tehadap ajaran agama adalah berbakti kepada suaminya. Selanjutnya suami selalu ditempatkan lebih superiordan sebagai pihak yang mengendalikan perilaku istrinya.

Beberapa penjelasan di atas menggambarkan bahwa kekerasan terjadi berawal dari budaya patriarkhi yang mendudukkan laki-laki sebagai pihak yang lebih berkuasa atas perempuan. Budaya patriarkhi telah dikonstruksikan selama bertahun-tahun, sehingga dominansi laki-laki terhadap perempuan dianggap sebagai kodrat yang harus diterima, Masing-masing individu merasa bahwa ada keharusan untuk berperilaku sesuai dengan norma masyarakat yang berlaku. Akibatnya ada perasaan tidak layak pada istri yang tidak menuruti kehendak suami, dan suami pun merasa tidak pantas jika harus mengalah kepada istrinya. Hal tersebut sering memicu munculnya kekerasan, karena istri merasa terpaksa melakukan sesuatu yang tidak diinginkan, suami menganggap dirinya sebagai pihak yang harus menentukan perilaku istri.

\section{Upaya-Upaya Untuk Mencegah Kekerasan Terhadap istri}

Kekerasan berbasis jender disebabkan okh konstruksi budaya, sehingga pendekatan yang penting dalam mengatasi kekerasan terhadap perempuan dengan mengubah ideologi patriarkhi menjadi ideologi keadilan jender. Pernyataan tersebut didukung oleh Adinkrah (2001) yang menemukan bahwa struktur sosial patriarkhis cenderung berhubungan dengan kekerasan terhadap perempuan. Laki-laki sejak kecil lebih diberi peluang untuk bertindak agresif dibanding perempuan yang lebih dikonstruksi untuk mengalah dan tergantung kepada laki-laki. Akibatnya, laki-laki terbiasa menggunakan cara-cara kekerasan untuk memenuhi keinginan maupun menyelesaikan permasalahan.

Berpijak dari gender-related violence, maka upaya-upaya dapat dilakukan secara preventif untuk meningkatkan kesadaran mengenai hak-hak perempuan, memberikan program untuk meningkatkan keadilan jender. serta upaya-upaya untuk memberdayakan perempuan yang secara budaya menjadi pihak yang tersubordinasi.

Salah satu program untuk meng-upayakan kesadaran terhadap keadilan jender adalah pendidikan mengenai hak-hak perempuan yang dirancang untuk meningkatkan kesadaran perempuan akan hak-haknya (www.sigi.org/Programs, 16-2-2004). Kesadaran terhadap hak-hak perempuan diharapkan dapat benar-benar tertanam dalam diri perempuan maupun laki-laki, sehingga lakilaki juga pertu memahami hak-hak perempuan. Perem-puan seharusnya tidak segan untuk mengemukakan hak-hak yang selama ini mungkin tidak disadarinya. Hal terse but dapat menghindarkan perempuan dari tindak kekerasan suami, karena suami juga memahami hak-hak istrinya.

Program lain yang dimaksudkan untuk mencegah kekerasan terhadap perempuan telah dilakukan oleh Youth Relationships Projact (YRP) di London, Ontario, Canada (Jaffe dkk, 1996). Program ini membantu wanita muda untuk memahami hak-haknya, memperhatikan keselamatan dirinya, serta mengekspresikan diri secara asertif. Selanjutnya juga dijelaskan bahwa YRP dirancang untuk membangun kekuatan ketahanan (resilfience), dan ketrampilan mengatasi masalah, serta meningkatkan penyelesaian konflik dengan tidak menggunakan kekerasan. Penelitian Greene \& Navarro (dalam Quina, 
2000) menemukan bahwa ketrampilan asertif membantu perempuan untuk terhindar dari korban kekerasan. Hasil penelitian tersebut didukung oleh hasil penelitian Eisler dkk (dalam Rodriques dkk, 2001) yang menemukan bahwa perempuan yang mendapatkan pelatihan asertivitas menjadi lebih percaya diri, mandiri, mampu menemukan identitas diri dan lebih kompeten dalam berbagai aspek kehidupan. Pendekatan lain yang dapat diasumsikan untuk mencegah kekerasan adalah manajemen konflik dan pelatihan pencegahan kekerasan yang dikembangkan oleh Maxwell (1998). Materi pelatihan dirancang untuk mengajarkan orang agar lebih efektif dalam menghadapi situasi kekerasan, serta mengendalikan respon agresif mereka terhadap konflik.

Model prevensi yang dilakukan oleh institute for Choosing Non-Violence juga menggunakan model belajar kognitif, yaitu orang dapat mengubah perilakunya melalui belajar hal-hal baru, terutama memahami hubungan kekuasaan, serta ketrampilan yang dapat dipraktekkan dalam kehidupan seharihari (Matthews, 2000). Model Choosing NonViolence (CNV) bertujuan untuk meningkatkan kesadaran akan kekerasan yang dialami, mencari penyebab, seperti budaya, media, atau stres, serta untuk mencari model interaksi alternatif. Selain itu model CNV menggambarkan suatu kerangka kerja yang terintegrasi untuk memahami dan mencegah kekerasan terhadap perempuan. Pelatihan ini memiliki tema-terna dan isu-isu penting yang meliputi: mendefinisikan kekerasan, dinarnika dan efek kekerasan dalam keluarga, pesanpesan jender, media, komunikasi (khususnya mengenai perasaan), stres, disiplin, dan implementasi praktis. Peserta diberi sejumlah materi yang berhubungan dengan isu-isu tersebut dan mengarahkan melalui ceramah atau diskusi, latihan individual, diskusi kelompok, dan video.

Model CNV tersebut mendasari pemikiran bahwa kekerasan terhadap perempuan dapat dikurangi atau dicegah dengan melakukan pern-belajaran baik secara kognitif maupun behavioral kepada istri agar terhindar dari kekerasan. Menu rut penulis model CNV juga dapat dimplementasikan dalam proses pembelajaran kepada laki-laki, dalan bentuk pelatihan yang melibatkan perempuan dan laki-laki untuk meningkatkan cara menghadapi konflik tanpa menggunakan kekerasan. Asurnsi tersebut didukung oleh hasil penelitian Cloitre dkk (2002) yang membuktikan bahwa pelatihan ketrampilan sosial dapat memperkuat manajemen diri, meningkatkan hubungan interpersonal dan mem-perbaiki hubungan. Model ini sebenarnya dapat juga diterapkan di Indonesia melalui program-program persiapan menjelang pernikahan yang selama ini sering dilakukan oleh Kantor Urusan Agarna (KUA). Pendidikan mengenai jender dapat disosialisasikan kepada laki-laki dan perempuan melalui program tersebut alau program pernberdayaan yang lain, sehingga pemahaman terhadap jender diharapkan dapat mencegah kemungkinan terjadi kekerasan dalarn rumah tangga.

Beberapa kajian di atas mengimplikasikan seolah-olah perempuan yang lebih didorong untuk menghentikan tindakan kekerasan. Sebenarnya prevensi terhadap tindakan kekerasan tentu saja mem-butuhkan kesadaran laki-laki yang dalam banyak kasus merupakan pelaku kekerasan. Namun harus diakui bahwa akibat ketidakadilan jender pad a saat ini banyak merugikan perempuan, sehingga perempuan yang mesti lebih gigih memperjuangkan hak-haknya. Jika perernpuan lebih memiliki kompetensi dałam menghadapi kekerasan, maka perempuan juga akan mampu meraberikan pem-belajaran kepada laki-laki (suami) agar mampu berinteraksi tanpa kekerasan. Perempuan perlu memberikan penolakan yang tegas terhadap kekerasan yang diterima. Dalam hal ini perempuan dapat melakukan sosialisasi jender kepada laki-laki (suami) untuk meningkatkan hubungan setara, sehingga mampu menyadarkan keduanya untuk menyelesaikan masalah tanpa kekerasan. 


\section{KESIMPULAN}

Persoalan kekerasan terhadap perempuan yang berpangkal pada ketidakadilan jender di masyarakat tidak hanya membutuhkan pengesahan hukum dan perundangundangan yang selama ini sudah ada. Akan tetapi menuntut perubahan kultural yang membutuhkan waktu panjang. Strategi yang dipertukan adalah melakukan kampanye dan pendidikan (pelatihan) kepada masyarakat baik laki-laki maupun perempuan untuk mengubah persepsi dan ideologi masyarakat. Bentuk pendidikan kritis perlu dilakukan untuk menggeser ideologi ketidakadian jender yang diyakini masyarakat menjadi ideologi keadilan jender.

\section{DAFTAR PUSTAKA}

Adinkrah, M. 2001. Patriarchal Family ideology and Female Homicide Victimization in Fiji. Jour nal of Comparative Family Studies. (Volume: 32, 283).

Bainar (editor), 1998. Wacana Perempuan dalam Keindonesiaan dan Kemodernan. Yogyakarta: PT Pustaka ClDESINDO bekerja sama dengan Universitas Islam indonesia dan Yayasan IPP SDM.

Cloitre, M., Koenen, K. C. \& Han, H. 2002. Skills Training in Affective and Interpersonal Regulation Followed by Exposure: Phase-Based Treatment for PTSD Related to Childhood Abuse. Journal of Consulling and Clinical Psychology. (Volume: 70: 1067-1074).

Cookfair, J.M. 1996. Nursing Care in The Community. St. Louis: Mosby-Year Book, Inc.

Djannah, F., Rustam, Nurasiah, Sitorus, M. \& Batubara, C. 2002. Kekerasan terhadap Istri. Yogyakarta: LkiS.
Jaffe, P. G., Lemon, N. K. D., Sandler, J. \& Wolfe, D. A. 1996. Working Together To End Domestic Violence. Tampa, Florida: Mancorp Publishing, Inc.

Lips, H. M. 1988. Sex and Gender. An introduction. Mountain View California: Mayfield Publishing Company.

Matthews, N. A 2000. Generic Violence Prevention and Gendered Violence: Getting The Message to Mainstream Audiences. Violence Against Women. Thousand Oaks (Volume: 6, 311-331).

Maxwell, J. P. 1998. The Effects of Interpersonal Oppressive Violence on Women and Children: Implications for Conflict Management and Violence Prevention Training. Peace and Conflict. (Volume: 4: 155).

Nevid, J. S., Rathus, S. A. \& Greene, B. 1997. Abnormal Psychology in a Changing world. New Jersey: Prentice-Hall Inc.

Nylen, L. \& Heimer, G 1999. Sweden's Respons to Domestic Violence. FBI Law Enforcement Bulletin, Washington. (Volume: 68: 19-24).

Quina, K., Harlow, L. L., Morokoff, P. J., Burkholder, G \& Deiter. P. J. 2000. Sexual Communication in Relationships: When Words Speak Louder Than Actions. Sex Roles: A Journal of Research. (Volume: 532).

Richmon, M. 1992. Masculine and Feminine. Gender Roles Over The Lif New York: Abbot, McGraw Hill, Inc.

Rodriques, G., Johnson, S. W. \& Combs, D. C. 2001. Significant Variables Associated with Assertiveness Among Hispanic College Women. Journal of instructional Psychology. (Volume: 28). 
Sulastri, E. 2001. Studi Eksploratif tentang Kekerasan terhadap Perempuan dalam Rumah Tangga di Kabupaten Indramayu Jawa Barat. Skripsi (Tidak Diterbitkan). Yogyakarta: Fakultas Psikologi UII.

Yoshioka, M. R., DiNoia, J. \& Ullah, K. 2001. Attitudes Toward Marital Violence: An Examination of Four Asian Communities. Violence Against Women. Thousand Oaks, (Volume: 7, 900-926). 2004. Aniaya Istri Dilaporkan Polisi. Kedaulatan Rakyat, 11 Pebruari 2004. 2004. Tersangka Pembakar Istri, Stress. Kedaulatan Rakyat, 12 Pebruari 2004.
2004. Hamil 5 Bulan, Emi Ditikam Suami. Kedaulatan Rakyat, 16 Pebruari 2004.

Sumber dari Website:

Komitmen Pemerintah untuk Menghapus Kekerasan terhadap Perempuan. www menegppgoid, 06-02-2004.

Ending Violence Against Women. Population Reports. wwwinf of or health, 18-22004.

Claiming Our Rights: Human Rights Education Manual www.sigiorg/Programs, 16-2004. 